\title{
Active Avoidance Learning Requires Prefrontal Suppression of Amygdala-Mediated Defensive Reactions
}

\author{
Justin M. Moscarello ${ }^{1}$ and Joseph E. LeDoux ${ }^{1,2}$ \\ ${ }^{1}$ Center for Neural Science, New York University, New York, New York 10003, and ${ }^{2}$ Emotional Brain Institute, Nathan Kline Institute, Orangeburg, New \\ York 10962
}

Signaled active avoidance (AA) paradigms train subjects to prevent an aversive outcome by performing a learned behavior during the presentation of a conditioned cue. This complex form of conditioning involves pavlovian and instrumental components, which produce competing behavioral responses that must be reconciled for the subject to successfully avoid an aversive stimulus. In signaled AA paradigm for rat, we tested the hypothesis that the instrumental component of AA training recruits infralimbic prefrontal cortex (ilPFC) to inhibit central amygdala (CeA)-mediated Pavlovian reactions. Pretraining lesions of ilPFC increased conditioned freezing while causing a corresponding decrease in avoidance; lesions of CeA produced opposite effects, reducing freezing and facilitating avoidance behavior. Pharmacological inactivation experiments demonstrated that ilPFC is relevant to both acquisition and expression phases of AA learning. Inactivation experiments also revealed that AA produces an ilPFC-mediated diminution of pavlovian reactions that extends beyond the training context, even when the conditioned stimulus is presented in an environment that does not allow the avoidance response. Finally, injection of a protein synthesis inhibitor into either ilPFC or CeA impaired or facilitated AA, respectively, showing that avoidance training produces two opposing memory traces in these regions. These data support a model in which AA learning recruits ilPFC to inhibit CeA-mediated defense behaviors, leading to a robust suppression of freezing that generalizes across environments. Thus, ilPFC functions as an inhibitory interface, allowing instrumental control over an aversive outcome to attenuate the expression of freezing and other reactions to conditioned threat.

\section{Introduction}

The acquisition of signaled active avoidance (AA) behavior depends on two sequential forms of learning (Mowrer and Lamoreaux, 1946). Initially, subjects undergo Pavlovian threat conditioning, in which a previously neutral conditioned stimulus (CS) comes to predict an aversive unconditioned stimulus (US) (Pavlov, 1927; Rescorla and Wagner, 1972). In subsequent trials, subjects acquire an instrumental avoidance contingency, in which a behavior performed during the CS prevents US delivery (Mowrer and Lamoreaux, 1946; Cain and LeDoux, 2008). In a typical experiment, a rat is placed in a divided chamber and trained to shuttle between compartments during an auditory CS to avoid a footshock US.

Intriguingly, these two forms of conditioning yield opposing behavioral endpoints, and early trials of AA training are characterized by a conflict between mutually exclusive responses to the CS. Although pavlovian information is essential for signaled AA

\footnotetext{
Received May 29, 2012; revised Dec. 15, 2012; accepted Jan. 7, 2013.

Author contributions: J.M.M. and J.E.L. designed research; J.M.M. performed research; J.M.M. analyzed data; J.M.M. and J.E.L. wrote the paper.

This project was supported by National Institute of Mental Health Grants F32MH094061 (J.M.M.) and R01MH038774 (J.E.L.) and National Institute on Drug Abuse Grant R01DA029053 (J.E.L.). We acknowledge Claudia Farb for her important contributions to our c-Fos experiment, as well as Christopher Gonzalez for his assistance in conducting these studies.

The authors declare no competing financial interests.

Correspondence should be addressed to Justin M. Moscarello, Center for Neural Science, New York University, 4 Washington Place, New York, NY 10003. E-mail: jmm31@nyu.edu.

DOI:10.1523/JNEUROSCI.2596-12.2013

Copyright $\odot 2013$ the authors $\quad 0270-6474 / 13 / 333815-09 \$ 15.00 / 0$
}

behavior, it produces freezing and other conditioned reactions that obstruct avoidance. As the instrumental contingency is acquired, subjects achieve a robust suppression of these reactive behaviors (Solomon and Wynne, 1954; Cain and LeDoux, 2008), which remain attenuated even when the CS is presented in environments that do not allow subjects to perform the avoidance response (Kamin et al., 1963). Thus, by gaining control over US delivery, subjects successfully inhibit the expression of deeply instated behavioral reactions that normally prevail in situations of expected threat (Fanselow and Lester, 1988; Blanchard et al., 2005; LeDoux, 2012).

This study explores the neural substrates by which competing CS-evoked responses are resolved over the course of signaled AA training. Varying lines of evidence implicate the central nucleus of the amygdala (CeA) in the production of the conditioned freezing response (Wilensky et al., 2006; Ciocchi et al., 2010; Haubensak et al., 2010) that directly opposes AA (Choi et al., 2010; Lazaro-Munoz et al., 2010). In contrast, stimulation of the infralimbic prefrontal cortex (ilPFC) blunts the excitatory response of brainstem-projecting CeA neurons (Quirk et al., 2003; Likhtik et al., 2005) crucial for the expression of freezing (Ciocchi et al., 2010; Duvarci et al., 2011). Complementary studies suggest a role for ilPFC in forms of learning that attenuate the freezing response (Morgan and LeDoux, 1995; Quirk et al., 2000; Santini et al., 2004; Sierra-Mercado et al., 2011), whereas other experiments demonstrate the involvement of ilPFC in the detection of aversive behavioral contingencies (Amat et al., 2005, 2006). As such, we hypothesize that the conflict between pavlovian and 
instrumental processes is resolved by ilPFC, which exerts feedforward inhibition on CeA to suppress the conditioned reactions that oppose avoidance. The experiments described below use lesion and pharmacological techniques to assess the role of ilPFC and CeA in a signaled AA paradigm previously established in this laboratory. Results suggest that ilPFC is a key substrate by which behavioral control can alter the expression of CeA-mediated defensive reactions.

\section{Materials and Methods}

Animals

Subjects were 166 naive male Sprague Dawley rats (Hilltop Laboratories) weighing 250-300 g at the time of arrival. Rats were individually housed in plastic tubs with ad libitum access to food and water and kept on a $12 \mathrm{~h}$ light/dark cycle (lights on at 8:00 AM). All procedures were approved by the New York University Animal Welfare Committee.

\section{Apparatus}

Signaled AA apparatus. Signaled AA training occurred in six identical Plexiglas and metal rectangular shuttle boxes $(50.8 \times 25.4 \times 30.5 \mathrm{~cm}$, length $\times$ width $\times$ height) separated into two equal compartments by a metal divider placed halfway along the length of the chamber (Coulbourn Instruments). A passage in the divider $(8 \times 9 \mathrm{~cm}$, width $\times$ height $)$ allowed animals to move freely between compartments. The floor was comprised of conductive stainless steel bars. Two speakers mounted on opposite walls of the chamber delivered a $5 \mathrm{kHz}, 70 \mathrm{db}$ tone CS; a $0.7 \mathrm{~mA}$ footshock US was administered via the floor by a scrambled shocker. The chamber was lit by two $0.5 \mathrm{~W}$ light bulbs, one in each compartment. The shuttle box was housed within a lager sound-attenuating cubicle.

Shuttling (movement from one compartment to the other) was monitored by two infrared arrays, each comprising five emitter-detector pairs and located on either side of the metal divider. Sessions were also recorded on DVD by a pair of black and white infrared cameras, one in each compartment.

CS test apparatus. Two distinct contexts were used to test the animals' response to the CS outside the avoidance training environment. These contexts were created in eight identical square chambers $(26 \times 28 \times 20$ $\mathrm{cm}$, length $\times$ width $\times$ height; Coulbourn Instruments) made of clear Plexiglas and metal with a floor of stainless steel bars. In one context, a black Plexiglas square was placed over the floor bars, and the chamber was scented with peppermint. In the other, the floor bars were left exposed, a pattern of black and white stripes was placed behind the two clear Plexiglas walls and the chamber was scented with lavender. In both contexts, a tone CS identical to the one used in the avoidance environment was delivered from a wall-mounted speaker. Sessions were recorded using a black and white infrared camera anchored to the ceiling. Each chamber was housed within a sound-attenuating cubicle.

\section{Surgery}

Electrolytic lesions. Animals were anesthetized with a mixture of ketamine $(75 \mathrm{mg} / \mathrm{kg})$ and xylazine $(10 \mathrm{mg} / \mathrm{kg})$ and mounted into a stereotaxic frame. The skull was exposed and bilateral boreholes were made. A stainless steel electrode, insulated except for a $0.5 \mathrm{~mm}$ exposed tip, was lowered into the target brain regions to produce a lesion. Coordinates for ilPFC were anteroposterior $(\mathrm{AP})+2.5$, mediolateral $(\mathrm{ML}) \pm 0.6$, and dorsoventral (DV) -5.2 ; $1 \mathrm{~mA}$ of current was passed for $10 \mathrm{~s}$. Coordinates for plPFC were $\mathrm{AP}+3.2, \mathrm{ML} \pm 0.6$, and $\mathrm{DV}-4.0 ; 1 \mathrm{~mA}$ of current was passed for $10 \mathrm{~s}$. Coordinates for CeA lesion were AP $-1.8,-2.3$, $-2.8, \mathrm{ML} \pm 3.8, \pm 4.0, \pm 4.4$, and DV $-8.4 ; 0.5 \mathrm{~mA}$ of current was passed for $10 \mathrm{~s}$ at all drop points. For sham lesions, the electrode was lowered into place, but no current was passed. Animals were allowed to recover for $14 \mathrm{~d}$ before the initiation of behavioral training.

ilPFC and CeA cannula implantation. Animals were anesthetized with a mixture of ketamine/xylazine (dose as above), mounted into the stereotaxis, and implanted with two 22 gauge chronic guide cannula aimed at ilPFC or CeA. Coordinates for ilPFC were AP +2.8, ML \pm 3.1 , and DV -3.8 , with the cannula angled at $30^{\circ}$ (as in Sierra-Mercado et al., 2011). Coordinates for CeA were AP $-2.3, \mathrm{ML} \pm 4.0$, and $\mathrm{DV}-8.2$. A stainless steel obdurator was used to keep the cannula patent before injection.
Animals were allowed $14 \mathrm{~d}$ recovery before the initiation of behavioral training.

\section{Drugs and intracranial infusions}

Muscimol. The $\mathrm{GABA}_{\mathrm{A}}$ agonist muscimol was used to inactivate ilPFC. Muscimol was dissolved in aCSF and adjusted to $\mathrm{pH}$ 7.4. The dose used was $0.02 \mu \mathrm{g} / 0.2 \mu \mathrm{l}$ per side for all inactivation experiments. Animals were gently restrained and fitted with internal cannulae attached to a $1 \mu \mathrm{l}$ Hamilton syringe with polyethylene 20 tubing. An infusion pump administered the injection at a rate of $0.1 \mu \mathrm{l} / \mathrm{min}$ for $2 \mathrm{~min}$; the internal cannulae were left in place for another minute to allow for diffusion. All muscimol injections began $20 \mathrm{~min}$ before behavioral testing.

Anisomycin. The protein synthesis inhibitor anisomycin was used to impair consolidation in the ilPFC and CeA. Anisomycin was slowly dissolved in aCSF using $\mathrm{HCl}$; once sufficiently suspended in vehicle, the $\mathrm{pH}$ was adjusted to 7.4 using $\mathrm{NaOH}$. The dose used was $12.5 \mu \mathrm{g} / 0.2 \mu \mathrm{l}$ per side. Infusion techniques were identical to those used for muscimol, except that all anisomycin injections began $20 \mathrm{~min}$ after the cessation of behavioral testing.

\section{Behavioral procedures}

Signaled AA training. On the day before the initiation of training, all animals were habituated to the shuttle box for $1 \mathrm{~h}$; shuttling (movement from one subcompartment to the other) was recorded as a measure of baseline locomotor activity. Twenty-four hours later, the first of five consecutive daily avoidance training sessions began. Each session started with a 5 min acclimation period in which no stimuli were presented. The first trial of the first session was a Pavlovian trial, a $15 \mathrm{~s}$ tone CS preceded a $1 \mathrm{~s}$ footshock US, regardless of whether the animal performed the avoidance response (shuttling) during CS presentation. This allowed all animals to acquire the Pavlovian contingency at the same point in training. All subsequent trials were avoidance trials. The CS lasted a maximum of $15 \mathrm{~s}$ and was followed immediately by a US that lasted a maximum of $15 \mathrm{~s}$. If the animal shuttled during CS presentation, the tone terminated immediately and the US was not delivered; this was scored as an avoidance response. If the animal shuttled during US presentation, the shock immediately ceased, and this was scored as an escape response. Each session comprised of 30 avoidance CSs with a varying intertrial interval that averaged $120 \mathrm{~s}$.

Stimulus delivery and data collection were fully automated by a personal computer running GraphicState software (Coulbourn Instruments). Freezing was scored offline by a trained rater blinded to group and was defined as immobility with the exception of respiratory movement. For freezing during signaled avoidance training, every fifth avoidance CS starting with the first was scored and then averaged to generate a representative sample for a given session. On the first day, freezing to the initial pavlovian CS was scored as a baseline but not included in the average for that day.

c-Fos test. This experiment involved three groups, including standard ilPFC and sham lesion groups, as well as a sham lesion group in which the animal was placed in the avoidance apparatus for the same period as the other groups but received no conditioning. This last group served as a control for baseline levels of c-Fos activity evoked by handling, the apparatus, etc. Animals were habituated to the shuttle box before receiving two normal sessions of avoidance training. The third session involved 15 CSs with no USs to test the effects of the CS on CeA c-Fos immunoreactivity without the potential confound of shock. Ninety minutes after the cessation of this session, animals were deeply anesthetized and perfused.

CS test. In this experiment, animals received only three consecutive daily sessions of signaled avoidance, which is the normative time to asymptote in the avoidance paradigm used here. On the day before the initiation of avoidance training, animals were habituated to the chamber for $1 \mathrm{~h}$ and then to one of two alternate contexts for $1 \mathrm{~h}$. After the first avoidance session, animals were placed back in the alternate context to which they were habituated on the preceding day, allowed to acclimate for $5 \mathrm{~min}$ and then played a $2 \mathrm{~min}$ CS. On the following day, after the second avoidance training session, animals were habituated for $1 \mathrm{~h}$ to the alternate context that they did not previously experience. Finally, after the third and final avoidance session, animals were infused with either 
muscimol or vehicle into ilPFC 20 min before being placed in the context to which they had been habituated the day before. After $5 \mathrm{~min}$ of acclimation, animals were exposed to a 2 min CS. Subjects experienced the two alternate contexts in a counterbalanced order.

Freezing was scored offline, as described above. Defecation was used as a corroborating measure of conditioned fear; animals were removed from the chamber immediately after both CS test sessions, and the number of boluses was counted by the experimenter.

Shock-free probe session. Animals were habituated to the shuttle box and trained for two sessions of avoidance before a third and final session in which no US was delivered. Either muscimol or vehicle was infused into the ilPFC 20 min before this shock-free session, which consisted of 30 unreinforced CSs that were inactivated by shuttling. Animals received no shock at any point; the trial was otherwise identical to a normal AA session.

\section{Perfusion and histology}

Cannula/lesion placement. At the end of each behavioral experiment, animals were deeply anesthetized and transcardially perfused with $10 \%$ buffered Formalin. Brains were removed and sliced into $40 \mu \mathrm{m}$ sections using a cryostat. Sections were then stained with cresyl violet and examined under a microscope. A camera lucida was used to demarcate the extent of lesions and to determine cannula placement.

c-Fos immunochemistry. Ninety minutes after the end of behavioral testing in the c-Fos experiment, animals were deeply anesthetized and transcardially perfused with $4 \%$ paraformaldehyde. Brains were cut into $40 \mu \mathrm{m}$ sections on a freezing microtome; sections containing ilPFC were stained with cresyl violet to determine the extent of lesion, whereas sections containing CeA were processed for c-Fos. Free-floating sections were washed with PBS ( $0.01 \mathrm{M}, \mathrm{pH}$ 7.6, at room temperature) between the different treatments and stained using the $\mathrm{ABC}$ method. Sections were incubated for $1 \mathrm{~h}$ in $1 \%$ bovine serum albumin (Sigma) to block nonspecific binding and then incubated for $24 \mathrm{~h}$ in the c-Fos primary antibody: 1:10,000 c-Fos (polyclonal rabbit anti-c-Fos; Santa Cruz Biotechnology) $+0.2 \%$ Triton X-100 (Sigma) $+1 \%$ BSA. Sections were incubated for 30 min in the secondary antibody anti-rabbit IgG (Elite-Anti-Rabbit Vector Kit; Vector Laboratories) and for $30 \mathrm{~min}$ in the avidin-biotin-horseradish peroxidase complex (Elite-Anti Rabbit Vector Kit; Vector Laboratories). Staining was visualized using the chromogen Very Intense Purple (Vector Laboratories) $+0.01 \% \mathrm{H}_{2} \mathrm{O}_{2}$ (Vector Laboratories). Sections were then dehydrated and coverslipped.

c-Fos-positive cells were recorded by visual inspection in a light microscope. The CeA-containing section quantified from each animal was most similar to bregma -2.28 . At $4 \times$ magnification, the right CeA was framed in the center four squares of a $10 \times 10$ grid. Magnification was then increased to $20 \times$ for quantification. c-Fos counts were made by two trained raters blinded to experimental condition. The average of these two counts was used as the score for each animal.

\section{Statistical analyses}

Avoidance and freezing data derived from lesion, muscimol, and anisomycin experiments involving a multi-session learning curve were analyzed using a two-way mixed-design ANOVA with a between-subjects factor of group (lesion or drug, depending on the experiment) and a within-subjects factor of session. When appropriate, Bonferroni's post hoc tests were used for multiple comparisons of group differences across individual sessions. For the CS test experiment, two-way ANOVA was followed by two-tailed $t$ test for post hoc analysis, because these data only required a single comparison. c-Fos data were analyzed with a one-way ANOVA, followed by Bonferroni's post hoc tests comparing lesion with sham and lesion with box control groups. Two-tailed $t$ tests were also used to analyze data from experiments that required the comparison of two means only, such as the shock-free probe experiment and behavioral data from the c-Fos experiment.

\section{Results}

\section{Electrolytic lesions and signaled AA}

An initial series of experiments used electrolytic lesions to assess the role of the prefrontal cortex and amygdala in the transition from conditioned freezing to AA (greatest and least extent of all lesions displayed in Fig. 1). In the first of these, rats were prepared with electrolytic ilPFC lesions $(n=8)$ or sham lesions $(n=8)$ before five daily sessions of AA training. A two-way ANOVA with a between-subjects factor of lesion and a within-subjects factor of session was performed on CS-evoked freezing data collected during AA training. This analysis revealed a main effect for lesion $\left(F_{(1,14)}=14.78, p=0.002\right)$, indicating that ilPFC lesion increased conditioned freezing across sessions (Fig. 2A). An identical analysis was performed on avoidance responses from the same animals. ANOVA revealed a main effect for lesion $\left(F_{(1,14)}=17.32\right.$, $p=0.001)$, indicating that ilPFC lesion reduced the number of avoidance responses across sessions (Fig. $2 B$ ). Thus, ilPFC suppresses pavlovian defense reactions, thereby facilitating the acquisition of the avoidance response.

Because some ilPFC lesions extended dorsally into the ventral portions of the adjacent prelimbic prefrontal cortex (plPFC), a control experiment targeting plPFC was performed. ANOVA revealed no differences between lesion $(n=8)$ and sham $(n=8)$ groups for either freezing or avoidance (Fig. $2 C, D$ ). It seems that plPFC lesions have no effect on avoidance training when conducted at a pretraining time point.

To examine the role of an important substrate of CS-evoked freezing, animals were prepared with electrolytic CeA lesions $(n=7)$ or sham lesions $(n=7)$ before AA training. CS-evoked freezing from lesion and sham groups was analyzed using a twoway mixed-design ANOVA with a between-subjects factor of lesion and a within-subjects factor of session. This analysis revealed a lesion $\times$ session interaction $\left(F_{(4,48)}=6.19, p<0.001\right)$, and Bonferroni's post hoc tests confirmed a significant decrease in freezing by the lesion group during the first session $(p<0.01$; Fig. $2 E)$. An identical ANOVA was performed on avoidance responses from the same animals. This revealed a lesion $\times$ session interaction $\left(F_{(4,48)}=3.89, p=0.008\right)$, which Bonferroni's post hoc tests confirmed was caused by a significant increase in avoidance responses among lesion animals during the first session $(p<0.01$; Fig. $2 F)$. These data are commensurate with a wide body of evidence implicating CeA in Pavlovian threat conditioning (Wilensky et al., 2006; Ciocchi et al., 2010; Haubensak et al., 2010) and indicate that CeA underpins the conditioned reactions that oppose AA behavior.

To control for the possible locomotor effects of ilPFC and CeA lesions, subjects' shuttling behavior was recorded during habituation to the avoidance apparatus. ilPFC lesion animals shuttled a mean $69.5 \pm 4.5$ times, and their corresponding sham controls shuttled a mean $75.9 \pm 3.9$ times during the $1 \mathrm{~h}$ habituation session; two-tailed $t$ test found no difference between lesion and sham. CeA lesion animals shuttled a mean $91.4 \pm 9.3$ times, whereas their corresponding shams shuttled a mean $101 \pm 9.9$ times during habituation; two-tailed $t$ test found no difference between lesion and sham. These data suggest that lesions of ilPFC and CeA do not disrupt basic locomotion.

Together, these lesion data suggest opposite roles for ilPFC and $\mathrm{CeA}$ in the acquisition of signaled $\mathrm{AA}$, with ilPFC facilitating the avoidance response by attenuating conditioned freezing and CeA opposing avoidance by driving the expression of Pavlovian defensive reactions.

To examine whether the behavioral effects of ilPFC lesion are associated with changes in CeA activity, animals were prepared with ilPFC and sham lesions and given two normal sessions of signaled AA training before a test session comprised of 15 CSs with no USs. After this 15 CS test session, animals were killed and processed for c-Fos in CeA. c-Fos counts from ilPFC lesion $(n=$ 
8) and sham lesion $(n=8)$ groups were analyzed along with an additional sham lesion group $(n=8)$ that received no conditioning and served as a box control. Separate two-tailed $t$ tests revealed that animals with ilPFC lesions showed higher levels of CS-evoked freezing $(p=0.021$; Fig. $3 A$ ) and made fewer avoidance responses $(p=0.032$; Fig. $3 B)$ during the 15 CS test session. A one-way ANOVA performed on CeA c-Fos counts from ilPFC lesion, sham lesion, and box control groups revealed a significant main effect $\left(F_{(2,21)}=4.772, p=0.020\right)$ (Fig. 3C); Bonferroni's post hoc tests confirmed a significant increase in the ilPFC lesion group relative to shams $(p<0.05)$, as well as a significant increase in the ilPFC lesion group relative to box controls $(p<0.05)$. These data demonstrate that the effects of ilPFC lesion are associated with enhanced activity in CeA, implying that ilPFC inhibits freezing and facilitates avoidance by suppressing activity in a key substrate of Pavlovian defensive behavior.

\section{Pharmacological inactivation of ilPFC and signaled AA}

Although spatially discrete, lesions lack temporal precision, and electrolytic lesions destroy fibers of passage. To control for these issues, as well as to examine the role of ilPFC during the acquisition and expression phases of the AA learning curve, two temporary inactivation experiments were conducted. Inactivation of ilPFC was achieved by the intracranial microinjection of the $\mathrm{GABA}_{\mathrm{A}}$ agonist muscimol. In the first experiment, muscimol $(n=8)$ or vehicle $(n=8)$ was infused before the first session of avoidance training to assess the role of ilPFC in acquisition (cannula placement displayed in Fig. $4 A$ ). CS-evoked freezing from muscimol and vehicle groups was analyzed using a two-way ANOVA with a betweensubjects factor of drug and a withinsubjects factor of session. This analysis revealed a main effect for drug $\left(F_{(1,14)}=\right.$ 10.28, $p<0.001$ ), indicating that ilPFC muscimol caused a significant increase in freezing across five daily sessions of training (Fig. 5A). An identical ANOVA was performed on avoidance responses from the same animals. This analysis revealed a main effect for drug $\left(F_{(1,14)}=7.26, p=0.017\right)$, indicating that ilPFC muscimol caused a significant decrease in avoidance responses across training (Fig. $5 B$ ). These data suggest that a functioning ilPFC is required during the acquisition phase of AA learning for animals to effectively suppress freezing and achieve normal levels of avoidance behavior in subsequent sessions.

To examine the role of ilPFC during the expression phase of training, muscimol $(n=9)$ or vehicle $(n=9)$ was infused before

A

C

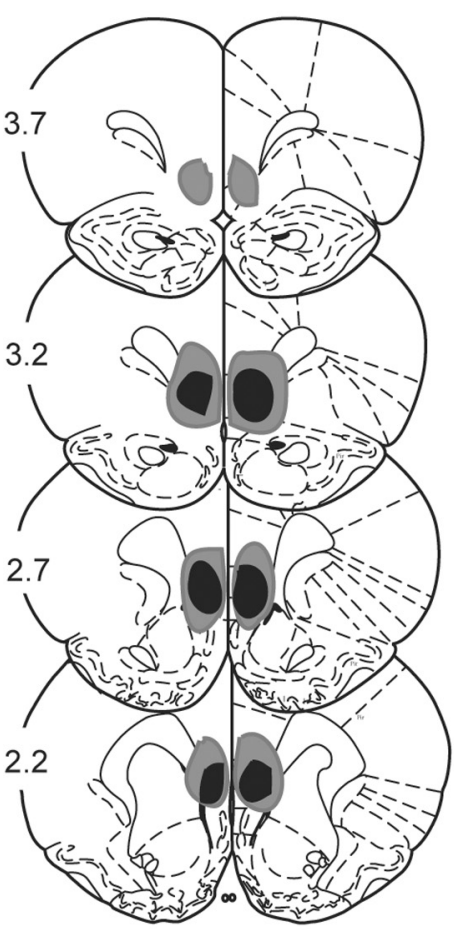

$\mathrm{B}$
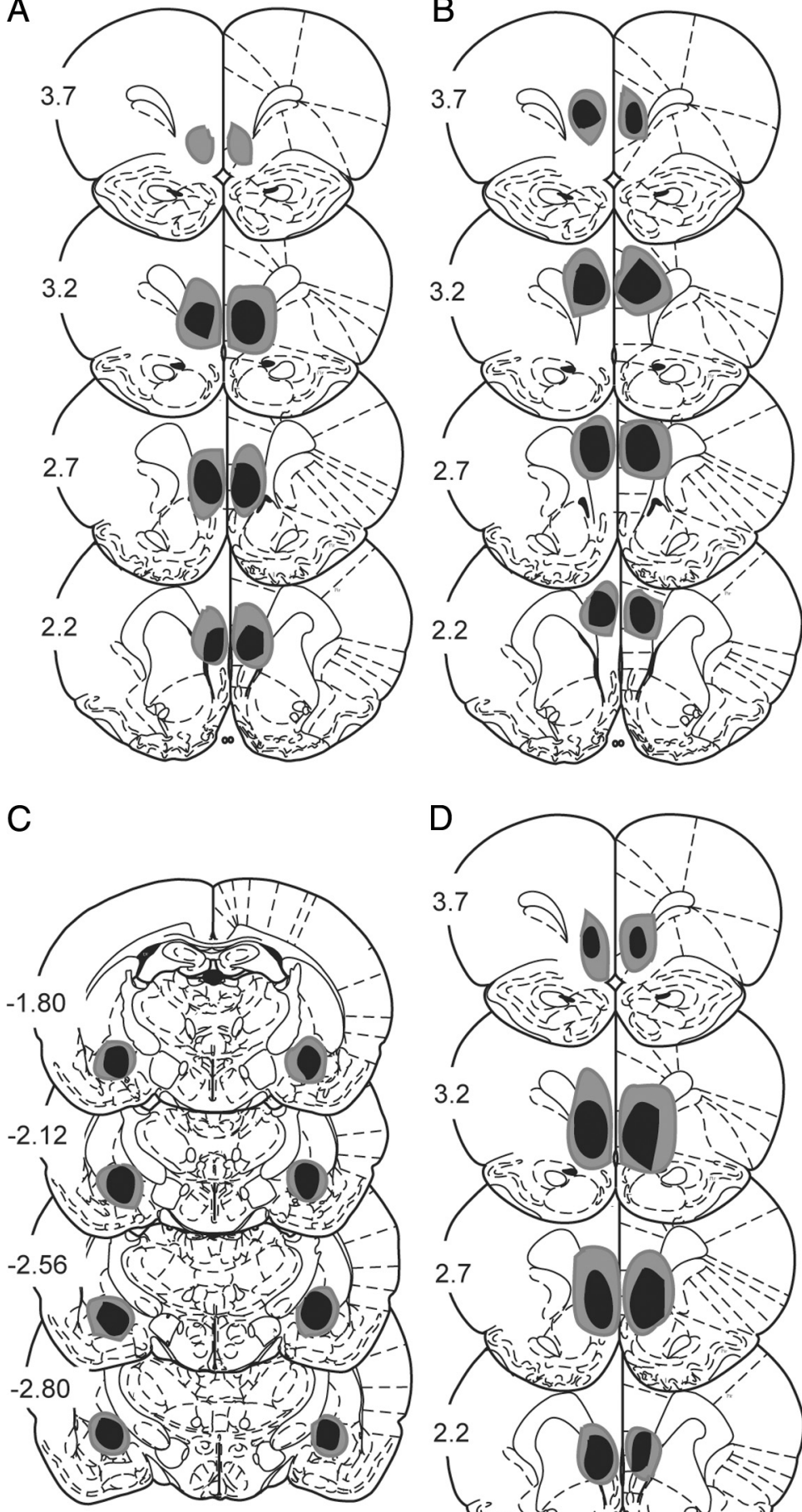

$\mathrm{D}$

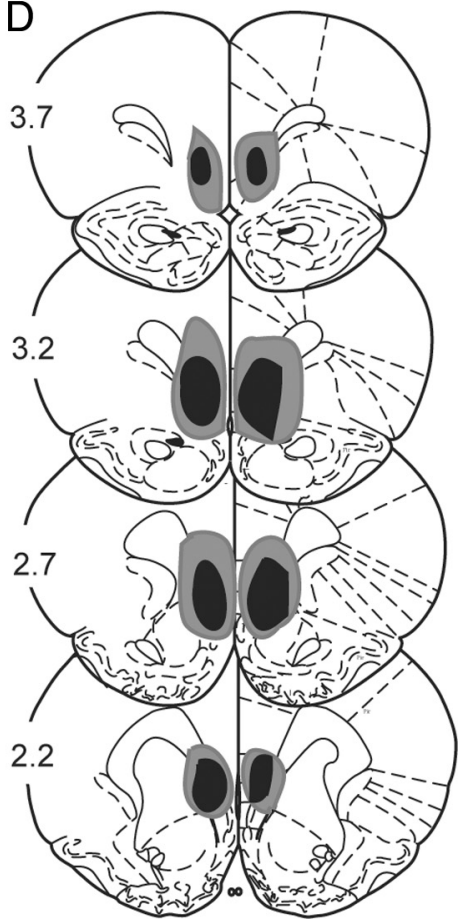

Figure 1. Lesion placements. Shaded areas represent the greatest (gray) and least (black) extent of electrolytic lesions; numbers reflect distance from bregma (in millimeters). Lesions $A$-C Cccurred before $5 \mathrm{~d}$ of signaled AA training, lesion $\boldsymbol{D}$ occurred before 2 d of signaled AA, followed by a 15 CS test for C-Fos. $\boldsymbol{A}$, ilPFC lesions. B, pIPFC lesions. C, CeA lesions. D, ilPFC lesions.

the fifth session of AA (cannula placement displayed in Fig. 4B). Animals were given an additional day of training to assess the lingering effects of muscimol treatment. Normal acquisition occurred over the first $4 \mathrm{~d}$ of training. CS-evoked freezing from the final three sessions of AA (sessions 4-6) was analyzed using a two-way ANOVA with a between-subjects factor of drug and a within-subjects factor of session. This analysis revealed a drug $X$ session interaction $\left(F_{(2,32)}=4.29, p=0.044\right)$, which Bonferroni's 

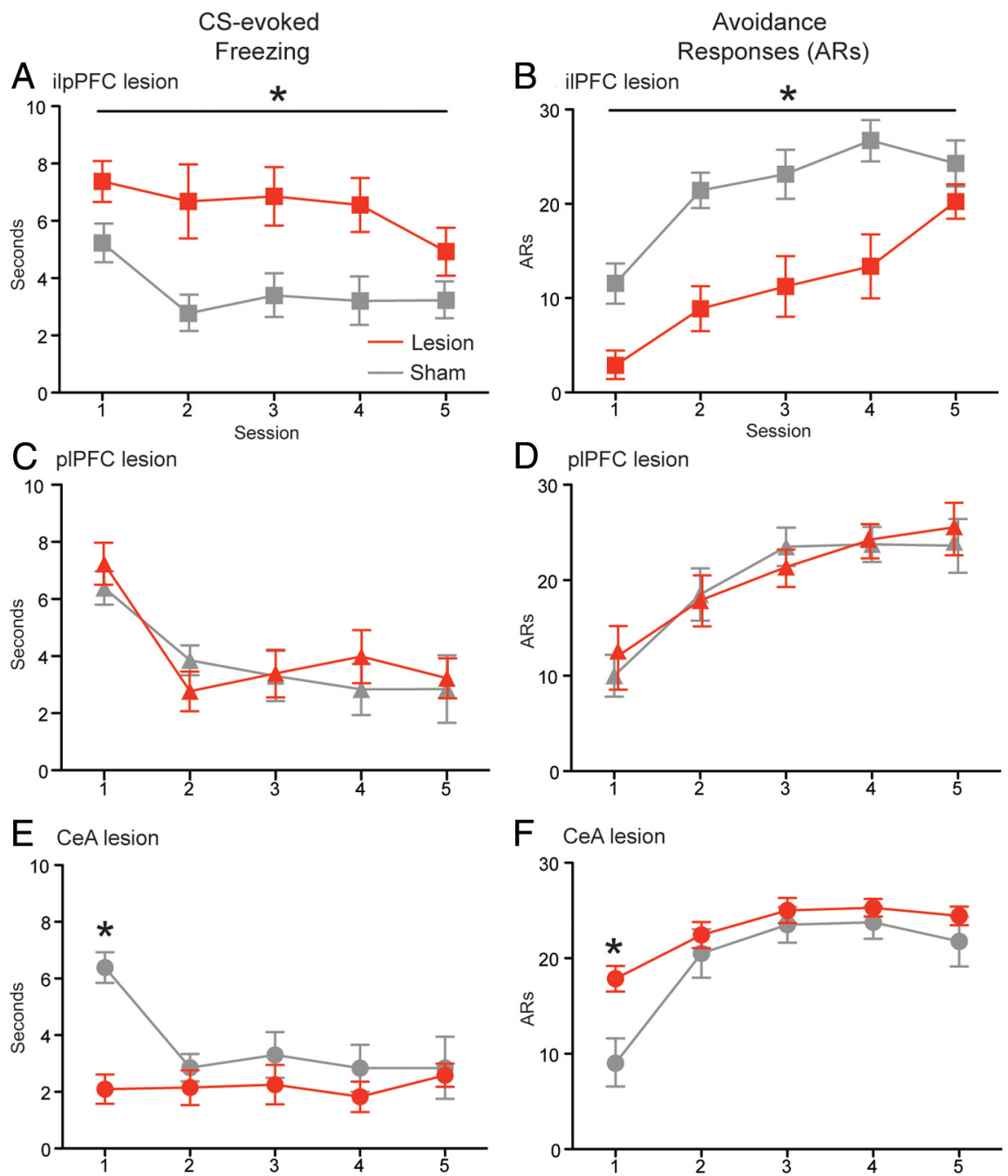

Figure 2. Effects of pretraining electrolytic lesions on mean \pm SEM freezing (left column) and mean \pm SEM avoidance responses (right column). $\boldsymbol{A}, \boldsymbol{B}$, ilPFC lesion $(n=8)$ and sham $(n=8) . \boldsymbol{C}, \boldsymbol{D}, \operatorname{pIPFC~lesion}(n=8)$ and sham $(n=8) . \boldsymbol{E}, \boldsymbol{F}$, CeA lesion $(n=7)$ and sham $(n=7) .{ }^{*} p<0.05$.

post hoc tests confirmed was driven by a significant increase in freezing among the muscimol group during the fifth session of training $(p<0.01$; Fig. $5 C)$. An identical ANOVA was performed on avoidance responses from the same animals. This analysis revealed a drug $X$ session interaction $\left(F_{(2,32)}=8.37, p=0.001\right)$, which Bonferroni's post hoc tests confirmed was driven by a significant decrease in the muscimol group relative to vehicle controls $(p<0.01$; Fig. $5 D)$. Although ilPFC remains relevant to AA during the expression phase of behavior, these results indicate that the effect of inactivation is transient once the response has been fully acquired.

Previous work suggests that AA training attenuates the expression of CS-evoked defensive reactions across environments, even in contexts that do not allow the avoidance response (Kamin et al., 1963). To confirm and extend this intriguing result, the effect of ilPFC inactivation on conditioned reactions was examined when the CS was presented in an alternate context, in which shuttling was not possible (cannula placement displayed in Fig. $4 C$ ). Animals were given three daily sessions of avoidance training (Fig. 6A); a CS test was conducted after both the first and third sessions in two unique environments. Muscimol $(n=8)$ or vehicle $(n=8)$ was infused into ilPFC before the second and final CS test. Freezing data from the CS tests were analyzed using a two-way ANOVA with a betweensubjects factor of drug and a withinsubjects factor of test. This analysis revealed a drug $\times$ test interaction $\left(F_{(1,14)}=17.22\right.$, $p=9.001)$, which two-tailed $t$ test confirmed was driven by an increase in freezing in the muscimol group during the second CS test $(p<0.01$; Fig. $6 B)$.

As a corroborating measure, defecation during the CS test was also measured. These data were analyzed with a two-way ANOVA identical to the one used to analyze freezing. This revealed a drug $\times$ test interaction $\left(F_{(1,14)}=19.73, p<0.001\right)$, which two-tailed $t$ test confirmed was driven by a significant increase in the muscimol group relative to vehicle controls during the second session $(p<0.01$; Fig. $6 C$ ). Thus, as AA training progresses, the expression of Pavlovian reactions is strongly attenuated by ilPFC even when the animal encounters the CS in environments that do not permit avoidance behavior.

Data from the acquisition and expression experiments suggest that ilPFC inactivation increased the animal's latency to escape the US. ilPFC muscimol injection before the first session of AA training yielded an average escape latency of $1.63 \pm 0.12 \mathrm{~s}$ compared with $0.82 \pm 0.35 \mathrm{~s}$ in vehicle-injected controls; two-tailed $t$ test revealed that muscimol-treated subjects took longer to shuttle during the US ( $p<0.001$; data not shown graphically). A statistically significant increase was also observed when muscimol was injected into ilPFC before the fifth session, with an average escape latency of $1.82 \pm 0.32$ in drug-treated animals and $0.93 \pm 0.27$ in vehicle-treated controls; two-tailed $t$ test confirmed increased escape latencies in ilPFC inactivated subjects $(p=0.008$; data not shown graphically). Because this escape effect is caused by a manipulation that increases freezing and decreases avoidance, these data open the possibility that prolonged contact with footshock disrupts AA behavior. To control for this, the effects of ilPFC inactivation were tested on a US-free probe session conducted after two normal sessions of AA training (cannula placement displayed in Fig. 4D). Mean CS-evoked freezing during this session was analyzed with a two-tailed $t$ test, which revealed a significant increase between the muscimol $(n=7)$ and control $(n=7)$ groups $(p<0.001$; Fig. $6 E)$. Two-tailed $t$ test performed on avoidance responses from the same animals revealed a significant decrease among the muscimol group $(p<0.001$; Fig. $6 F)$. Thus, ilPFC inactivation increases freezing and decreases avoidance even when the US is not present, suggesting that prolonged US exposure cannot explain our results.

\section{Protein synthesis inhibition and signaled AA}

To ascertain whether ilPFC and CeA are important storage sites for the different types of information acquired during AA training, two separate experiments were performed in which the protein synthesis inhibitor anisomycin was injected into either ilPFC 
A CS-evoked Freezing

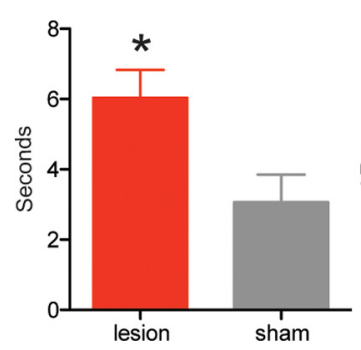

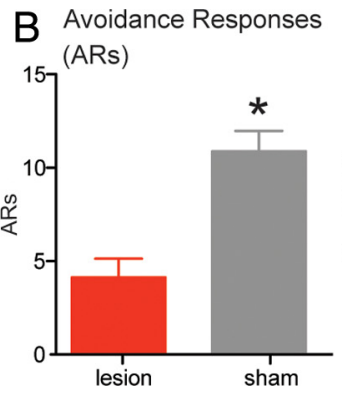

C CS-evoked c-Fos in CeA

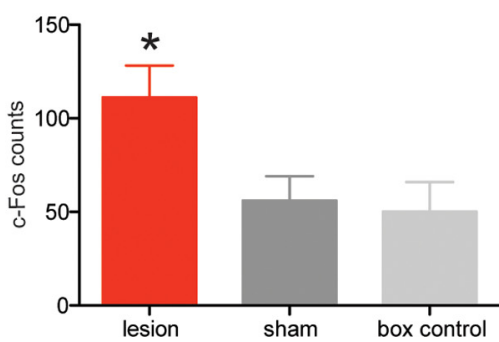

D CeA schematic

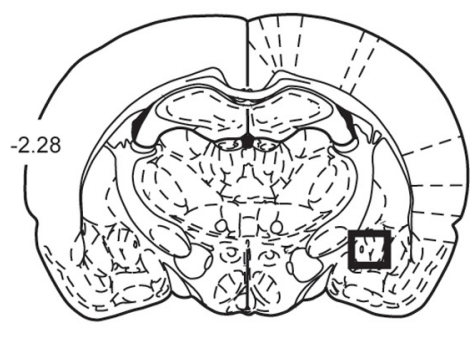

Figure 3. Effects of ilPFC lesion on behavior and CeA c-Fos activity during a 15 CS test session. $A$, Mean \pm SEM freezing. $\boldsymbol{B}$, Mean \pm SEM avoidance responses. C, Mean \pm SEM c-Fos counts in CeA. $D$, Schematic of CeA sections sampled for c-Fos; number reflects distance from Bregma in millimeters. ${ }^{*} p<0.05$.

A

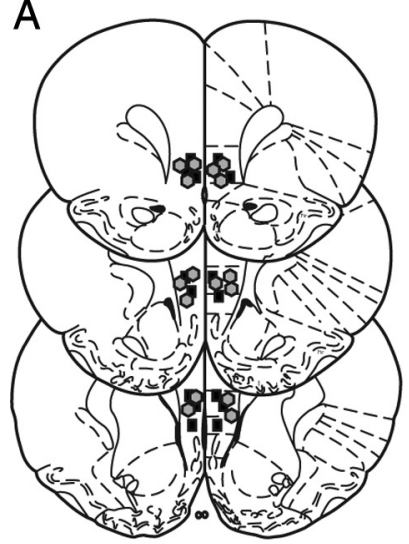

$\mathrm{D}$

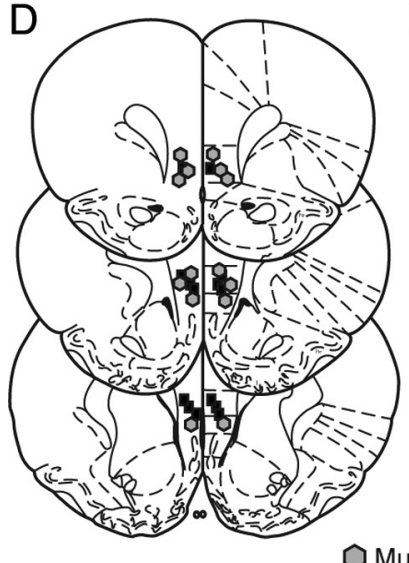

$\mathrm{B}$

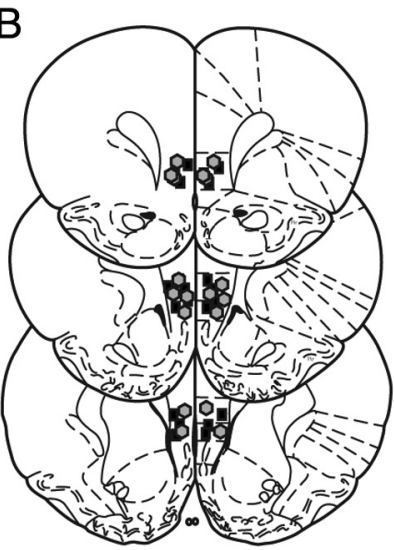

$\mathrm{E}$

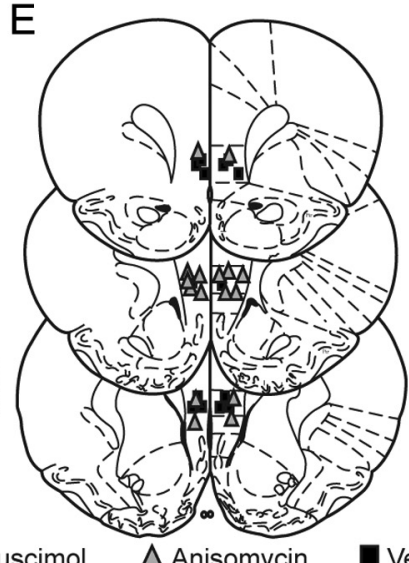

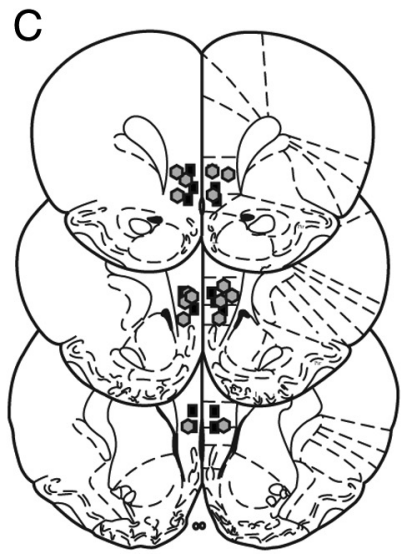

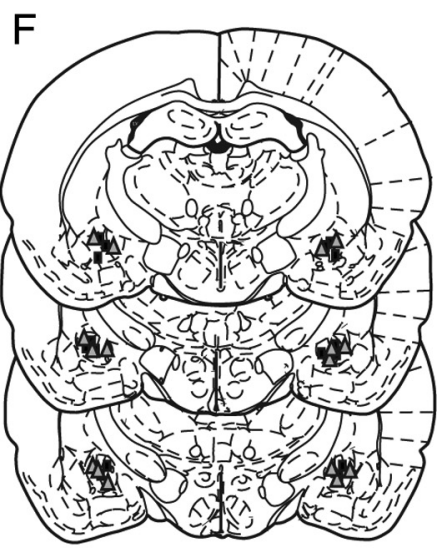

Vehicle

Figure 4. Cannula placements for all intracranial microinjection experiments. $A$, Cannula placement for ilPFC inactivation before the first session of AA training. $\boldsymbol{B}$, Cannula placement for ilPFC inactivation before the fifth session of AA training. C, Cannula placement for ilPFC inactivation before CS test in an alternate context. $\boldsymbol{D}$, Cannula placement for ilPFC inactivation before a shock-free probe session. $\boldsymbol{E}$, Cannula placement for ilPFC protein synthesis inhibition after the first session of AA training. $\boldsymbol{F}$, Cannula placement for CeA protein synthesis inhibition after the first session of AA training.

or CeA after the first avoidance session (ilPFC and CeA cannula placements displayed in Fig. 4E, F, respectively). For ilPFC injections, CS-evoked freezing data from anisomycin $(n=8)$ and vehicle $(n=8)$ groups were analyzed using a two-way ANOVA with a between-subjects factor of drug and a within-subjects factor of session. This analysis revealed a drug $\times$ session interaction $\left(F_{(4,56)}=2.56, p=0.046\right)$, which Bonferroni's post hoc tests confirmed was driven by a significant increase in freezing by the anisomycin group relative to controls on the second day of training $(p<0.01$; Fig. $7 A)$.

An identical ANOVA was performed on avoidance data from the same animals. This analysis revealed a drug $\times$ session interaction $\left(F_{(4,56)}=2.67, p=0.039\right)$, which Bonferroni's post hoc tests confirmed was driven by a significant decrease in the anisomycin group relative to vehicle controls during the second session of training $(p<0.01$; Fig. $7 B)$. Thus, protein synthesis inhibition in ilPFC after the first session of avoidance prevented the animal from effectively suppressing Pavlovian reactions in the subsequent session.

Opposite results were obtained when anisomycin was injected into CeA after the first session of AA training. Avoidance data from anisomycin $(n=8)$ and vehicle $(n=8)$ groups were analyzed using a two-way ANOVA with a between-subjects factor of drug and a within-subjects factor of session. This analysis revealed a drug $\times$ session interaction $\left(F_{(4,56)}=2.55, p=0.048\right)$, which Bonferroni's post hoc tests confirmed was driven by a sig- 
ilPFC Inactivation: 1st Session
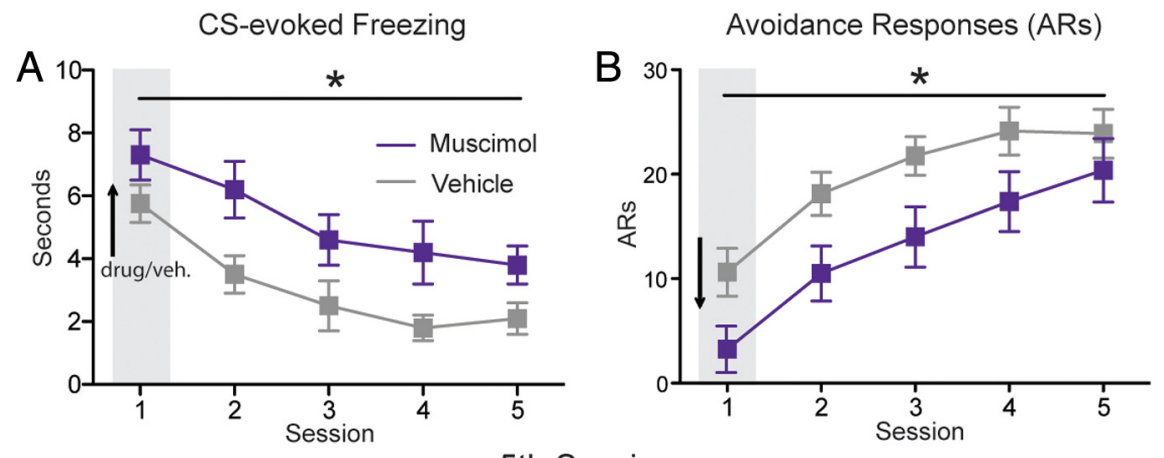

5th Session
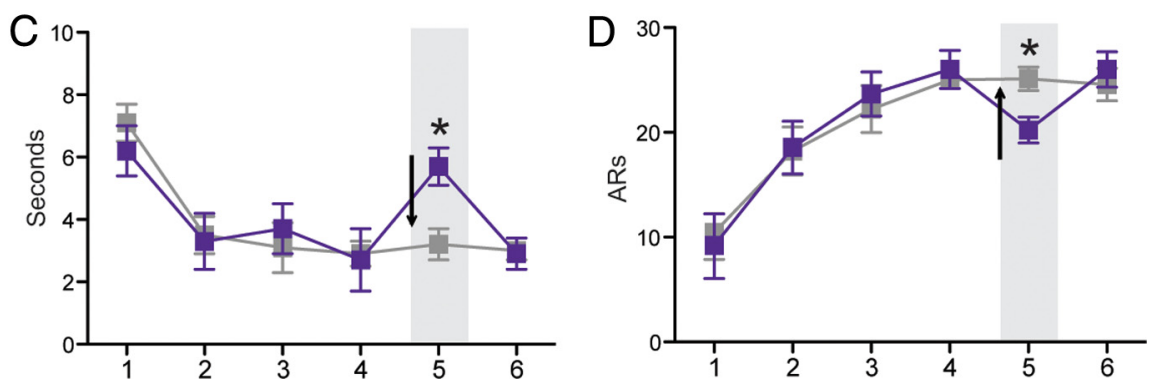

Figure 5. The effects of ilPFC inactivation on freezing (left column) and avoidance (right column) responses; light gray bars and black arrows indicate the session before which muscimol or vehicle was injected into ilPFC. Mean \pm SEM freezing $(\boldsymbol{A})$ and mean \pm SEM avoidance $(\boldsymbol{B})$ responses when ilPFC was infused with muscimol $(n=8)$ or vehicle $(n=8)$ before the first session of training. Mean \pm SEM freezing $(\boldsymbol{C})$ and mean \pm SEM avoidance $(\boldsymbol{D})$ responses when ilPFC was infused with muscimol $(n=9)$ or vehicle $(n=9)$ before the fifth session of training. ${ }^{*} p<0.05$.
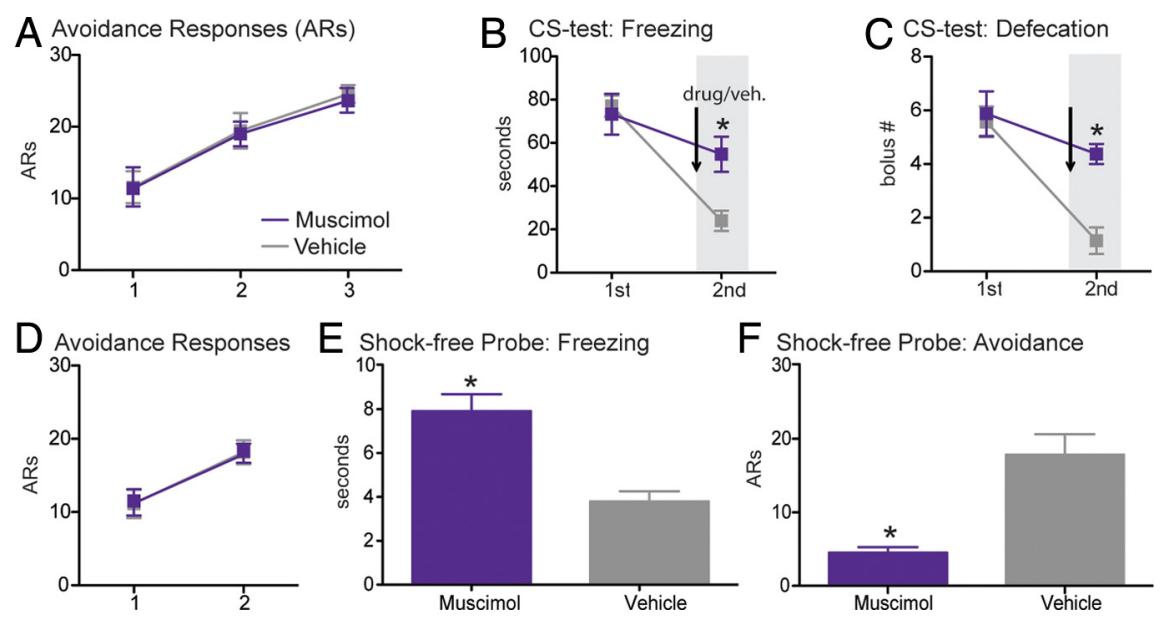

Figure 6. The effects of ilPFC inactivation on a CS test and a shock-free probe session. $A$, Mean \pm SEM avoidance responses during three sessions of AA training; animals were exposed to the $C S$ in an alternate environment after the first and third sessions. $B$, Mean \pm SEM CS-evoked freezing during two CS tests; the light gray bar and black arrow indicate that muscimol $(n=8)$ or vehicle $(n=8)$ was injected into ilPFC before the second test. C, Mean \pm SEM defecation (number of boluses) from the same subjects during two $C S$ tests. $D$, Mean \pm SEM avoidance responses during two sessions of AA training; this was followed by a shock-free probe session before which muscimol $(n=7)$ or vehicle $(n=7)$ was injected into ilPFC. $\boldsymbol{E}$, Mean \pm SEM CS-evoked freezing. $\boldsymbol{F}$, Mean \pm SEM avoidance responses during the shock-free probe session. ${ }^{*} p<0.05$.

nificant increase in the anisomycin group relative to controls on the second day of training ( $p<0.01$; Fig. $7 D)$, although an identical ANOVA revealed no differences for CS-evoked freezing at any point (Fig. 7C). Thus, plasticity in CeA opposes avoidance even when levels of conditioned freezing are relatively low. Together, these data suggest that ilPFC and CeA encode contrasting and dissociable memory traces during avoidance learning.

\section{Discussion}

This study confirms that signaled AA training leads to a robust suppression of Pavlovian threat reactions, in particular conditioned freezing. Lesion data demonstrate opposing roles for the ilPFC and CeA in AA learning, with ilPFC facilitating avoidance by inhibiting both CeA activity and the CS-evoked freezing it governs. Pharmacological inactivation experiments establish a role for ilPFC during both acquisition and expression phases of the AA learning curve, although the effect of inactivation only persists into subsequent drug-free sessions when administered during acquisition. Inactivation results also demonstrate that signaled AA produces an ilPFC-mediated reduction in CS-evoked freezing not only in the avoidance context, but also in alternate environments in which training did not occur. Finally, injection of a protein synthesis inhibitor into either ilPFC or CeA demonstrates that AA training creates two competing memory traces in these regions, facilitating or opposing the avoidance response, respectively. These data support a hypothetical model in which the instrumental avoidance contingency recruits ilPFC to exert feedforward inhibition on CeA, inhibiting those Pavlovian threat reactions that occlude AA behavior.

Although ilPFC can attenuate CeA activity and the reactive behaviors it governs (Milad and Quirk, 2002; Quirk et al., 2003; Likhtik et al., 2005), this must occur via an intervening mechanism for excitatory cortical inputs to inhibit amygdalar outputs. One candidate for the intermediary between ilPFC and CeA is the GABAergic intercalated cell masses (ICM) of the amygdala. Anatomical studies demonstrate that ilPFC projects to ICM (Sesack et al., 1989; Pinto and Sesack, 2008; Pinard et al., 2012), whereas anatomical and physiological data suggest that ICM innervate and inhibit CeA (Marowsky et al., 2005; Amir et al., 2011). Disinhibition of ilPFC causes immediate early gene induction in ICM (Berretta et al., 2005), and robust spiking occurs in ICM when ilPFC is electrically stimulated (Amir et al., 2011). Thus, ICM seem well situated to translate cortical excitation into the inhibition of CeA activity, thus attenuating the expression of Pavlovian reactions and facilitating AA. This hypothetical arrangement is consistent with prevalent models of amygdala function (LeDoux, 2000; Maren and Quirk, 2004), insofar as reduced CeA output causes a decrease in specific behavioral endpoints, while sparing the predictive relationship between CS and US necessary for successful avoidance learning. 
Our results suggest that ilPFC underpins an inhibitory form of behavioral learning that occurs during the acquisition of signaled AA. Posttraining anisomycin injections in ilPFC obstruct avoidance and enhance the expression of freezing in subsequent drug-free sessions, suggesting that ilPFC encodes a memory that directly opposes the expression of CeA-mediated conditioned behavior. Extinction also involves the learned inhibition of Pavlovian reactions (Myers and Davis, 2002; Herry et al., 2010) and depends on ilPFC to suppress CeA activity (Quirk et al., 2000; Santini et al., 2004; Sierra-Mercado et al., 2011). Despite similar substrates and behavioral endpoints, extinction and the suppression of freezing in AA are likely based on different types of information processing. Extinction learning occurs via unreinforced CS presentation, whereas the predictive relationship between CS and US must remain constant through the acquisition of AA for the cue to trigger the aversively motivated avoidance response. Instead, it seems more likely that acquired control over US delivery creates an inhibitory memory, which feeds back onto conditioned freezing. Thus, the instrumental response has a synergistic relationship with the suppression of Pavlovian reactions, with successful avoidance increasing the degree to which freezing is inhibited and vice versa. By moving through this upward spiral, the subject transitions from a state dominated by innate defensive behaviors to one in which instrumental action replaces CS-evoked reactions. Thus, ilPFC both responds to and facilitates the subject's degree of behavioral control by reducing the expression of those responses that obstruct AA.

We believe that our data implicate the instrumental avoidance contingency as a key trigger for the inhibition of pavlovian reactions in AA training, but there are other possible explanations for the diminution of conditioned freezing. Bolles (1970) proposed that freezing is maladaptive in the AA paradigm and is thus punished, effectively unmasking the avoidance response; other researchers argue that freezing is not amenable to punishment (Fanselow, 1994). It is also possible that the escape contingency plays an important role and that the ability to deactivate the shock by shuttling feeds back onto the expression of CS-evoked fear. Although our results demonstrate that ilPFC inactivation increases freezing and reduces avoidance even in a shock-free session, it is conceivable that the acquisition of instrumental escape does contribute to the formation of an inhibitory memory in ilPFC.

These data demonstrate that signaled AA training produces a broad reduction in defensive reactions evoked by the CS, even when presented in environments that do not permit the avoidance response. This result emphasizes the degree to which instrumental control over the US can alter the animal's response to cues that predict it. The literature on coping behavior in humans and animals describes a dichotomy between "proactive" and "reactive” responses to stressful stimuli (Koolhaas et al., 1999). Proactive coping is characterized by behavioral strategies designed to ${ }^{*} p<0.05$
ilPFC Protein Synthesis Inhibition
S-evoked Freezing

- Anisomycin

- Vehicle

T

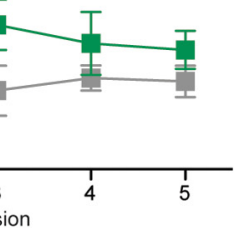

CeA Protein Synthesis Inhibition

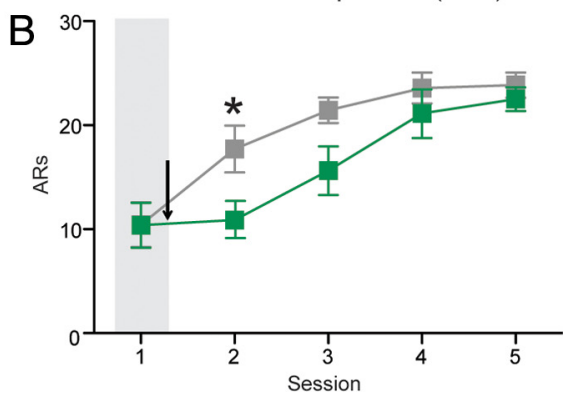

son

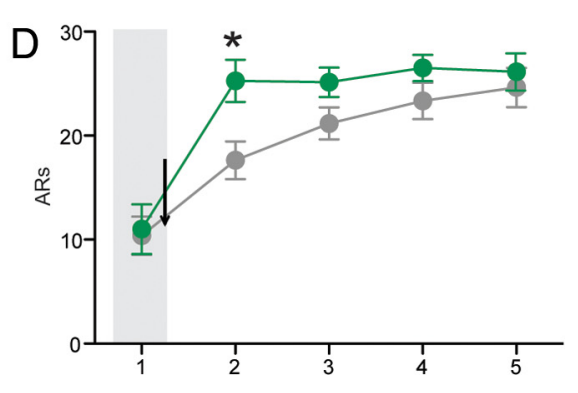

Figure 7. The effects of local protein synthesis inhibition on signaled AA training; light gray bars and black arrows indicate that and mean \pm SEM avoidance $(\boldsymbol{D})$ responses when anisomycin $(n=8)$ or vehicle $(n=8)$ was injected into CeA after the first session.

influence or control an individual's environment, whereas reactive coping involves more traditional "fear" or "anxiety" responses, such as withdrawal or immobility (Henry and Stephens, 1977; Koolhaas et al., 1999). Thus, by teaching subjects to prevent an aversive outcome with an instrumental behavior, signaled AA training causes a robust and pervasive transition from a reactive to a proactive coping style. Because reactive coping is associated with deleterious health outcomes (Koolhaas et al., 1999), this research highlights ilPFC, as well as its putative primate homolog the subgenual cingulate (Wallis, 2012), as an important target for therapies designed to facilitate adaptive coping strategies.

In summary, the Pavlovian and instrumental components of AA training produce competing behavioral outputs, which the subject resolves by attenuating the expression of conditioned reactions that obstruct the avoidance response. Data presented here suggest that this process depends on ilPFC, which selectively inhibits the expression of CeA-mediated pavlovian threat reactions in a manner that preserves the representation of the CS-US relationship. Although freezing is one of the rodent's primary defenses against imminent danger, it serves to increase the animal's contact with the aversive US in the AA paradigm. The acquisition of behavioral control over US delivery creates an inhibitory memory that effectively suppresses conditioned freezing, allowing instrumental behavior to predominate. Thus, ilPFC is part of an adaptive circuit that allows learned information to guide behavior when innate responses are ultimately detrimental.

\section{References}

Amat J, Baratta MV, Paul E, Bland ST, Watkins LR, Maier SF (2005) Medial prefrontal cortex determines how stressor controllability affects behavioral and dorsal raphe nucleus. Nat Neurosci 8:365-371. CrossRef Medline

Amat J, Paul E, Zarza C, Watkins LR, Maier SF (2006) Previous experience 
with behavioral control over stress blocks the behavioral and dorsal raphe nucleus activating effects of uncontrollable stress: role of ventral medial prefrontal cortex. J Neurosci 26:13264-13272. CrossRef Medline

Amir A, Amano T, Pare D (2011) Physiological identification and infralimbic responsiveness of rat intercalated amygdala neurons. J Neurophysiol 105:3054-3066. CrossRef Medline

Berretta S, Pantazopoulos H, Caldera M, Pantazopoulos P, Paré D (2005) Infralimbic cortex activation increases c-Fos expression in intercalated neurons of the amygdala. Neuroscience 132:943-953. CrossRef Medline

Blanchard DC, Blanchard RJ, Griebel G (2005) Defensive responses to predator threat in the rat and mouse. Curr Protoc Neurosci Chapter 8, Unit 8.19. CrossRef Medline

Bolles RC (1970) Species-specific defensive reactions and avoidance learning. Psychol Rev 77:32-48. CrossRef

Cain CK, LeDoux JE (2008) Brain mechanisms of Pavlovian and instrumental aversive conditioning. In: Handbook of anxiety and fear (Blanchard RJ, Blanchard DC, Griebel G, Nutt DJ, eds). New York: Elsevier.

Choi JS, Cain CK, LeDoux JE (2010) The role of the amygdala in the expression of auditory signaled two-way active avoidance. Learn Mem 17:139147. CrossRef Medline

Ciocchi S, Herry C, Grenier F, Wolff SB, Letzkus JJ, Vlachos I, Ehrlich I, Sprengel R, Deisseroth K, Stadler MB, Müller C, Lüthi A (2010) Encoding of conditioned fear in central amygdala inhibitory circuits. Nature 468:277-282. CrossRef Medline

Duvarci S, Popa D Paré D (2011) Central amygdala activity during fear conditioning. J Neurosci 31:289-294. CrossRef Medline

Fanselow MS (1994) Neural organization of the defensive behavior system for fear. Psychon Bull Rev 1:429-438.

Fanselow MS, Lester LS (1988) A functional behavioristic approach to aversively motivated behavior: predatory imminence as a determinant of the topography of defensive behavior. In: Evolution and learning (Bolles RC, Beecher MD, eds), pp 185-212. Hillsdale, NJ: Erlbaum.

Haubensak W, Kunwar PS, Cai H, Ciocchi S, Wall NR, Ponnusamy R, Biag J, Dong HW, Deisseroth K, Callaway EM, Fanselow MS, Lüthi A, Anderson DJ (2010) Genetic dissection of an amygdala microcircuit that gates conditioned fear. Nature 468:270-276. CrossRef Medline

Henry JP, Stephens PM (1977) Stress, health and the social environment: a sociobiological approach to medicine. Berlin: Springer.

Herry C, Ferraguti F, Singewald N, Letzkus JJ, Ehrlich I, Lüthi A (2010) Neuronal circuits of fear extinction. Eur J Neurosci 31:599-612. CrossRef Medline

Kamin LJ, Brimer CJ, Black AH (1963) Conditioned suppression as a monitor of fear of the CS in the course of avoidance training. J Comp Physiol Psych 56:497-501. CrossRef Medline

Koolhaas JM, Korte SM, De Boer SF, Van Der Vegt BJ, Van Reenen CG, Hopster H, De Jong IC, Ruis MA, Blokhuis HJ (1999) Coping styles in animals: current status in behavior and stress-physiology. Neurosci Biobehav Rev 23:925-935. CrossRef Medline

Lazaro-Munoz G, LeDoux JE, Cain CK (2010) Sidman instrumental avoidance initially depends on lateral and basal amygdala and is constrained by central amygdala-mediated Pavlovian processes. Biol Psychiatry 15: 1120-1127. CrossRef Medline

LeDoux J (2012) Rethinking the emotional brain. Neuron 73:653-676. CrossRef Medline

LeDoux JE (2000) Emotion circuits in the brain. Annu Rev Neurosci 23: 155-184. CrossRef Medline
LeDoux JE, Iwata J, Cicchetti P, Reis DJ (1988) Different projections of the central amygdaloid nucleus mediate autonomic and behavioral correlates of conditioned fear. J Neurosci 8:2517-2529. Medline

Likhtik E, Pelletier JG, Paz R, Paré D (2005) Prefrontal control of the amygdala. J Neurosci 25:7429-7437. CrossRef Medline

Maren S, Quirk GJ (2004) Neuronal signaling of fear memory. Nat Rev Neurosci 5: 844-852. CrossRef Medline

Marowsky A, Yanagawa Y, Obata K, Vogt KE (2005) A specialized subclass of interneurons mediates dopaminergic facilitation of amygdala function. Neuron 48:1025-1037. CrossRef Medline

Milad MR, Quirk GJ (2002) Neurons in medial prefrontal cortex signal memory for fear extinction. Nature 420:70-74. CrossRef Medline

Morgan MA, LeDoux JE (1995) Differential contribution of dorsal and ventral medial prefrontal cortex to the acquisition and extinction of conditioned fear in rats. Behav Neurosci 109:681-688. CrossRef Medline

Mowrer OH, Lamoreaux RR (1946) Fear as an intervening variable in avoidance conditioning. J Comp Psychol 39:29-50. CrossRef Medline

Myers KM, Davis M (2002) Behavioral and neural analysis of extinction. Neuron 36:567-584. CrossRef Medline

Pavlov IP (1927) Conditioned reflexes. London: Routledge and Kegan Paul.

Pinard CR, Mascagni F, McDonald AJ (2012) Medial prefrontal cortical innervation of the intercalated nuclear region of the amygdala. Neuroscience 205:112-124. CrossRef Medline

Pinto A, Sesack SR (2008) Ultrastructural analysis of prefrontal cortical inputs to the rat amygdala: spatial relationships to presumed dopamine axons and D1 and D2 receptors. 213:159-175.

Quirk GJ, Russo GK, Barron JL, Lebron K (2000) The role of ventromedial prefrontal cortex in the recovery of extinguished fear. J Neurosci 20:62256231. Medline

Quirk GJ, Likhtik E, Pelletier JG, Paré D (2003) Stimulation of the prefrontal cortex decreases the responsiveness of central amygdala output neurons. J Neurosci 23:8800-8807. Medline

Rescorla RA, Wagner AR (1972) A theory of classical conditioning: variations in the effectiveness of reinforcement and nonreinforcement. In: Classical conditioning II current research and theory (Black AH, Prokasy WF, eds). New York: Appleton-Century-Crofts.

Santini E, Ge H, Ren K, Peña de Ortiz S, Quirk GJ (2004) Consolidation of fear extinction requires protein synthesis in the medial prefrontal cortex. J Neurosci 24:5704-5710. CrossRef Medline

Sesack SR, Deutch AY, Roth RH, Bunney BS (1989) Topographical organization of the efferent projections of the medial prefrontal cortex in the rat: an anterograde tract-tracing study with Phaseolus vulgaris leucogglutinin. J Comp Neurol 290:213-242. CrossRef Medline

Sierra-Mercado D, Padilla-Coreano N, Quirk GJ (2011) Dissociable roles of prelimbic and infralimbic cortices, ventral hippocampus, and basolateral amygdala in the expression and extinction of conditioned fear. Neuropsychopharmacology 36:529-538. CrossRef Medline

Solomon RL, Wynne LC (1954) (1954) Traumatic avoidance learning: the principles of anxiety conservation and partial irreversibility. Psychol Rev 61:353-385. CrossRef Medline

Wallis JD (2012) Cross-species studies of orbitofrontal cortex and valuebased decision-making. Nat Neurosci 15:13-19. CrossRef Medline

Wilensky AE, Schafe GE, Kristensen MP, LeDoux JE (2006) Rethinking the fear circuit: the central nucleus of the amygdala is required for the acquisition, consolidation and expression of Pavlovain fear conditioning. J Neurosci 26:12387-12396. CrossRef Medline 